\title{
Antioxidant and Antimicrobial Properties of Aqueous Extract from Dictyophora indusiata
}

\author{
V.O. Oyetayo ${ }^{1,2}$, C.-H. Dong ${ }^{1,3}$ and Y.-J. Yao ${ }^{*, 1,3}$
}

${ }^{I}$ Key Laboratory of Systematic Mycology and Lichenology, Institute of Microbiology, Chinese Academy of Sciences, Beijing 100101, China

${ }^{2}$ Department of Microbiology, Federal University of Technology, Akure, Nigeria

${ }^{3}$ Joint Laboratory of Medicinal and Edible Fungi, Institute of Microbiology, Chinese Academy of Sciences and Jiangsu Alphay Bio-technology Co. Ltd, Beijing 100101, China

\begin{abstract}
The antioxidant and antimicrobial properties of hot water extract (WE) obtained from Dictyophora indusiata were investigated. The free radical scavenging ability of WE on DPPH• was $97.35 \%$ at $2 \mathrm{mg} / \mathrm{ml}$ concentration. The reducing power of WE was moderate $(1.22$ at $2 \mathrm{mg} / \mathrm{ml})$. Similarly, the WE displayed average scavenging effect on hydroxyl radical $(52.28 \%$ at $2 \mathrm{mg} / \mathrm{ml})$ and superoxide anion scavenging effect $(48.64 \%$ at $2 \mathrm{mg} / \mathrm{ml})$. However, the WE exhibited a very weak ferrous ion chelating effect of $18.56 \%$ at $2 \mathrm{mg} / \mathrm{ml}$ concentration. Antimicrobial assay revealed that WE from D. indusiata can inhibit both bacteria and fungi used as indicators for antimicrobial effect at concentration of $200 \mathrm{mg} / \mathrm{ml}$. The results suggest that WE possess good antioxidant and antimicrobial properties.
\end{abstract}

Keywords: Antioxidant, Antimicrobial, Hot water, Dictyophora indusiata, Extract.

\section{INTRODUCTION}

Mushrooms possess high contents of qualitative protein, crude fibre, minerals and vitamins [1,2]. Apart from their nutritional potentials, mushrooms are also sources of physiologically beneficial bioactive substances that promote good health $[3,4]$. They produce a wide range of secondary metabolites with high therapeutic value [5]. Health promoting properties, e.g. antioxidant, antimicrobial, anticancer, cholesterol lowering and immunostimulatory effects, have been reported for some species of mushrooms [6-8]. Both fruiting bodies and the mycelium contain compounds with wideranging antioxidant and antimicrobial activities $[7,9,10]$.

As sources of antioxidants, edible mushrooms are desirable since they are safe to eat and known not to place additional stress on the body [4]. Hence, edible mushrooms serve as a good alternative to synthetic antioxidant such as butylhydroxyanisole (BHA) and butylhydroxytoluene (BHT) which are known to be carcinogenic $[11,12]$.

Mushrooms need antibacterial and antifungal compounds to survive in their natural environment [13]. Hence, they are rich sources of natural antibiotics. The activity of the exudates from mushroom mycelia against protozoa such as the parasite that causes malaria, Plasmodium falciparum $[14,15]$ and other microorganisms [13] had been reported. Chinese Shiitake mushroom (Lentinus edodes) has also been reported to possess both anti-tumor and antimicrobial properties [16]. Presently, most antimicrobial that are available are sourced

*Address correspondence to this author at the Key Laboratory of Systematic Mycology and Lichenology, Institute of Microbiology, Chinese Academy of Sciences, Beijing 100101, China; Tel: +86-10-64807496; Fax: +86-1064807518; E-mail: yaoyj@sun.im.ac.cn from microscopic fungi [13]. Based on the reports above, edible mushrooms may be the source of new antimicrobial that can combat the emergence of resistant microbial strains that is now rampant.

Dictyophora indusiata (Vent.) Desv. (झPhallus indusiatus Vent.) is an edible mushroom that is considered a good delicacy by the Chinese. The species is also known as "Veiled Lady Mushroom" and belongs to the family of Phallaceae Corda. The fruiting body begins as an "egg" stage, from which the phallic-looking basidioma emerges over the course of just a few hours. The antioxidant property of methanolic extract from $D$. indusiata had been reported [17]. Moreover, the antimicrobial property of ethyl acetate, ethanol, acetone and volatile oil extracts from Dictyophora species have also been reported [18, 19].

In the present study, in vitro experiments, such as DPPH • scavenging, reducing activity, hydroxyl ion and superoxide anion radicals scavenging ability and iron chelating activity, were performed to assess the antioxidant potential of aqueous extract from $D$. idusiata. Moreover, the antimicrobial potential of the extract was assessed against some selected pathogenic and food spoilage organisms. The present study will reveal the biopharmaceutical potential of aqueous extract obtained from $D$. indusiata.

\section{MATERIALS AND METHODOLOGY}

\section{Fungal Materials}

The fungal materials used in this study were dried fruit bodies of $D$. indusiata from a mushroom farm and bought in Gutian County, Fujian Province, People's Republic of China. The fruit bodies were further dried at $45{ }^{\circ} \mathrm{C}$ in the laboratory to a constant weight and ground into powder before the extraction process. 


\section{Chemicals}

2-deoxy-o-ribose and 1,1-diphenyl-2-picrylhydrazyl $(\mathrm{DPPH} \bullet)$, Folin-Ciocalteau-reagent, Gallic acid were purchased from Sigma-Aldrich (Steinheim, Germany); 2thiobarbituric acid (TBA) from Acros Organics (Geel, Belgium); ethylenediaminetetraacetic acid (EDTA), nystatin and tetracylcline from Amresco (Ohio, USA); sodium acetate trihydrate, acetic acid, hydrogen peroxide $\left(\mathrm{H}_{2} \mathrm{O}_{2}\right)$, trichloroacetic acid (TCA) and ascorbic acid from Beijing Chemical Reagents Company (Beijing, China); Ampicillin from Huabei Pharm., China; butylated hydroxytoluene (BHT) from China National Pharmaceutical Group Shanghai Chemical Reagents Company (Shanghai, China); detection Kit of superoxide anion radical scavenging activity from Nanjing Jiancheng Bioengineering Institute (Nanjing, China). All reagents were analytical grade.

\section{Hot Water Extraction Process}

The powdered $D$. indusiata was soaked in 10 part volume of distilled water at 95 to $100{ }^{\circ} \mathrm{C}$ for $2 \mathrm{~h}$. The mixture of water and the residue was centrifuged for $10 \mathrm{~min}$ at $3214 \mathrm{~g}$ to obtain the water extract. This procedure was repeated twice. The water extract was filtered through a filter-paper under pressure using a Millipore machine and the filtrate concentrated to one third of the total volume by using a rotary evaporator under reduced pressure at $50{ }^{\circ} \mathrm{C}$, and the resultant extract was lyophilized to dryness in vacuum. The lyophilized water extract (WE) powder was stored in dark at $4{ }^{\circ} \mathrm{C}$ before use.

\section{Antimicrobial Assay}

\section{Indicator Organisms Used for Antimicrobial Assay}

A total of 12 microbial strains made up of 8 bacteria, 2 yeasts and two moulds were used. The microbial strains were Bacillus subtilis ATCC 6633, Bacillus cereus CMCC1.1846, Alcaligenes faecalis CMCC1.1837, Escherichia coli ATCC25922, Staphylococcus aureus ATCC 6358P, Pseudomonas aeruginosa ATCC10145, Shigella dysenteriae CMCC 51252, Salmonella typhimurium CMCC 1.1174, Candida albicans ATCC10231, Cryptococcus neoformans 1038, Aspergillus niger 1349 and Aspergillus flavus 1348. Microbial strains were obtained from China General Microbial Culture Collection Centre (CGMCC).

\section{Antimicrobial Activity}

Antimicrobial activity of WE from $D$. indusiata was determined by the agar well diffusion method [8]. The bacterial strains used as indicator organism were cultivated on Nutrient Agar Medium at $30 \pm 1{ }^{\circ} \mathrm{C}$ for $24 \mathrm{~h}$ while the fungal strains were cultivated on Yeast Malt Extract Agar at $26 \pm 1$ ${ }^{\circ} \mathrm{C}$ for 48 to $72 \mathrm{~h}$. Aliquot of culture $(100 \mu \mathrm{l})$ was evenly spread on the surface of the solidified agar. Wells of $7 \mathrm{~mm}$ were bored in the agar with sterile cork borers. Extract dissolved in $10 \%$ dimethyl sulfoxide (DMSO) to the concentration of 10 to $200 \mathrm{mg} / \mathrm{ml}$ and filtered through $0.22 \mu \mathrm{m}$ membrane filter was introduced into the wells. A $100 \mu 1$ volume was placed in each well. The plates were incubated at $30 \pm 1{ }^{\circ} \mathrm{C}$ for $24 \mathrm{~h}$ for bacteria while the fungi were incubated at $26 \pm 1{ }^{\circ} \mathrm{C}$ for 48 to $72 \mathrm{~h}$. Tetracycline and ampicillin were used as standard antibacterial while nystatin was used as antifungal standard under the conditions specified for bacteria and fungi respectively. The diameter of the inhibition zones were measured in milliliters. Inhibition zones were measured in triplicates (three plates per indicator organism). Agar well in which $10 \%$ DMSO was added served as negative control. The inhibitory action of negative control was not visible.

\section{Assessment of Antioxidant Activities of Water Extrate}

Multimechanistic antioxidative assays as listed below were employed in assessing the antioxidant property of the WE from $D$. indusiata.

\section{Scavenging Effect of DPPH・Radicals}

Radical scavenging potential of WE was assessed using an ethanolic solution of the "stable" free radical, DPPH•. The method of Blois [20] was used in studying the effect of WE from $D$. indusiata on DPPH $\bullet$ radicals with some modifications. A solution of $\mathrm{DPPH} \bullet(0.5 \mathrm{mmol} / \mathrm{L})$ in ethanol and $0.05 \mathrm{~mol} / \mathrm{L}$ acetate buffer ( $\mathrm{pH} 5.5$ ) was prepared. Extract in solution $(0.1 \mathrm{ml})$ at different concentrations was mixed with $2 \mathrm{ml}$ of acetate buffer, $1.9 \mathrm{ml}$ of absolute ethanol and $1 \mathrm{ml}$ $\mathrm{DPPH} \bullet$ solution. The mixture was shaken immediately after adding $\mathrm{DPPH} \bullet$ and allowed to stand at room temperature in dark for $30 \mathrm{~min}$. The decrease in absorbance at $517 \mathrm{~nm}$ was measured using a UNICO 2100 spectrophotometer. BHT was used as positive control and the sample solution without $\mathrm{DPPH} \bullet$ was used as blank. The radical scavenging activity was measured as a decrease in absorbance of DPPH and calculated as:

$$
\text { Scavenging activity }(\%)=\frac{A b-(A s-A s b)}{A b} \times 100
$$

where $\mathrm{Ab}, \mathrm{As}$ and $\mathrm{Asb}$ are absorbances at $517 \mathrm{~nm}$ of DPPH of the blank, the extract or the control and the sample blank respectively.

\section{Measurement of Reducing Power}

The reducing power of WE from $D$. indusiata was determined by the method of Yen and Chen [21] with some modification. Briefly, extracts $(0.0625-2 \mathrm{mg} / \mathrm{ml})$ in PBS $(2.5$ $\mathrm{ml}, 0.2 \mathrm{~mol} / \mathrm{L}, \mathrm{pH}$ 6.6) were added to potassium ferricyanide $(2.5 \mathrm{ml}, 10 \mathrm{mg} / \mathrm{ml})$ and the mixture was incubated at $50{ }^{\circ} \mathrm{C}$ for $20 \mathrm{~min} .2 .5 \mathrm{ml}$ of $10 \mathrm{mg} / \mathrm{ml}$ trichloroacetic acid (TCA) was added and centrifuged at $1160 \mathrm{~g}$ for $10 \mathrm{~min}$. De-ionised water $(2.5 \mathrm{ml})$ was added to $2.5 \mathrm{ml}$ of the supernatant and $0.5 \mathrm{ml}$ of $1.0 \mathrm{mg} / \mathrm{ml}$ ferric chloride. The absorbance was measured at $700 \mathrm{~nm}$ against a blank in a spectrophotometer (UNICO 2100). Ascorbic acid was used as control. A higher absorbance of the reaction indicates a higher reducing power.

\section{Scavenging Effect of Hydroxyl Radical}

The determination of scavenging effect on hydroxyl radicals was carried out as described in Halliwell et al. [22]. The reaction mixture in a final volume of $1.0 \mathrm{ml}$, containing 0.4 $\mathrm{ml}$ of $20 \mathrm{mmol} / \mathrm{ml}$ sodium phosphate buffer ( $\mathrm{pH} 7.4), 0.1 \mathrm{ml}$ of $0.125-2 \mathrm{mg} / \mathrm{ml}$ extracts, $0.1 \mathrm{ml}$ of $60 \mathrm{nmol} / \mathrm{L}$ deoxyribose, $0.1 \mathrm{ml}$ of $10 \mathrm{mmol} / \mathrm{L}$ hydrogen peroxide, $0.1 \mathrm{ml}$ of $1 \mathrm{mmol} / \mathrm{L}$ ferric chloride, $0.1 \mathrm{ml}$ of $1.04 \mathrm{mmol} / \mathrm{L}$ EDTA and $0.1 \mathrm{ml}$ of 2 $\mathrm{mmol} / \mathrm{L}$ ascorbic acid was incubated at $37{ }^{\circ} \mathrm{C}$ for $1 \mathrm{~h}$. Solutions of $\mathrm{FeCl}_{2}$ and ascorbic acid were made up immediately before use in de-ionised water. The reaction was stopped by adding $1 \mathrm{ml}$ of $17 \mathrm{mmol} / \mathrm{L}$ thiobarbituric acid (TBA) and 1 $\mathrm{ml}$ of $17 \mathrm{mmol} / \mathrm{L}$ trichloroacetic acid (TCA). The mixture 
was boiled for $15 \mathrm{~min}$, cooled in ice and then the absorbance measured at $532 \mathrm{~nm}$ using a UNICO 2100 spectrophotometer. BHT was used as positive control while distilled water in place of extracts or BHT was used as blank and the sample solution without adding deoxyribose as sample blank.

$$
\text { Scavenging activity }(\%)=\frac{A b-(A s-A s b)}{A b} \times 100
$$

where $\mathrm{Ab}$, As and Asb are the absorbance at $532 \mathrm{~nm}$ of the blank, the extract or BHT and the sample blank without deoxyribose, respectively.

\section{Scavenging Effect of Superoxide Anion Radicals}

A commercial kit was used to assay this. Superoxide anion radicals were generated by xanthine/xanthine oxidase system and reacted with 2,4-iodiphenyl-3,4-nitrophenyl-5phenyltetrazolium chloride to form formazan, a colored compound which was spectrophotochemically quantified at $550 \mathrm{~nm}$. The production of formazan is inversely related to the superoxide anion radical scavenging activity of tested sample. The final results were expressed as the inhibition degree of formazan production. BHT was used as positive control and distilled water in place of extracts or BHT as blank. The percentage of inhibition of superoxide anion radicals was calculated using the formula below.

$$
\text { Scavenging activity }(\%)=\frac{A b-A s}{A b} \times 100
$$

where $\mathrm{Ab}$ is the absorbance of the blank without extract or $\mathrm{BHT}$ and As is the absorbance in the presence of extract or BHT.

\section{Ferrous ion Chelating Assay}

The chelation of ferrous ion by the extracts was ascertained by the methods previously described [23]. One millilitre of extracts $(0.25-8 \mathrm{mg} / \mathrm{ml})$ was mixed with $3.7 \mathrm{ml}$ of deionised water and then the mixture was reacted with ferrous chloride $(2 \mathrm{mmol} / \mathrm{L}, 0.1 \mathrm{ml})$ and ferrozine $(5$ $\mathrm{mmol} / \mathrm{L}, 0.2 \mathrm{ml}$ ) for $20 \mathrm{~min}$. The absorbance at $562 \mathrm{~nm}$ was determined spectrophotometrically. EDTA was used as positive control. Chelating activity on ferrous ion was calculated using the equation below:

$$
\text { Chelating Activity }(\%)=\frac{A b-A s}{A b} \times 100
$$

where $\mathrm{Ab}$ is the absorbance of the blank without extract or EDTA and As is the absorbance in the presence of extract or EDTA.

\section{Statistical Analysis}

All experiments were carried out in triplicate. Data obtained were analyzed by one way analysis of variance and means were compared by Duncan's multiple range test (SPSS 11.5 version). Differences were considered significant at $\mathrm{p}<0.05$.

\section{RESULTS}

\section{Antimicrobial Activity of Water Extrate}

Table 1 showed the antimicrobial activity of WE. Alcaligenes faecalis was the most susceptible bacterium while the least susceptible was $E$. coli. Among the fungi used as indicators for antimicrobial test, Candida albicans was more susceptible to the antimicrobial effect of WE than the others.

\section{DPPH・ Scavenging}

At $0.0625-2 \mathrm{mg} / \mathrm{ml}$ concentrations, WE exhibited scavenging ability of $18.12-97.58 \%$. Scavenging activities of D. indusiata were well pronounced at concentrations of $0.5 \mathrm{mg} / \mathrm{ml}$ to $2 \mathrm{mg} / \mathrm{ml}$ (Fig. 1). The free radical scavenging effect of WE was slightly higher than BHT at concentrations of 0.5 to $2 \mathrm{mg} / \mathrm{ml}$. WE exhibited concentration dependent free radical scavenging effect.

\section{Reducing Activity}

Reducing ability of WE was also concentration dependent (Fig. 2). However, ascorbic acid (positive control) exhibited a better and significantly different $(\mathrm{P}<0.05)$ reducing power than WE. The WE exhibited a fair reducing power of 0.63 at $0.125 \mathrm{mg} / \mathrm{ml}$ concentration and this increased to 1.22 at $2 \mathrm{mg} / \mathrm{ml}$ concentration.

\section{Hydroxyl ion Scavenging Activity}

WE from $D$. indusiata exhibited moderate and concentration dependent hydroxyl radical scavenging ability (Fig. 3).

\begin{tabular}{|c|c|c|c|c|}
\hline Microorganism & WE $(200 \mathrm{mg} / \mathrm{ml})$ & Ampicillin $(10 \mu \mathrm{g} / \mathrm{ml})$ & Tetracycline $(30 \mu \mathrm{g} / \mathrm{ml})$ & Nystatin $(40 \mu \mathrm{g} / \mathrm{ml})$ \\
\hline Escherichia coli & $4.0 \pm 1.0$ & $4.0 \pm 0.0$ & $10.7 \pm 0.6$ & NT \\
\hline Alcaligenes faecalis & $14.3 \pm 0.6$ & $10.0 \pm 0.5$ & $23.7 \pm 3.7$ & NT \\
\hline Salmonella typhimurium & $5.5 \pm 0.5$ & $8.7 \pm 0.5$ & $4.0 \pm 0.0$ & NT \\
\hline Shigella dysenteriae & $8.0 \pm 1.0$ & $9.0 \pm 1.0$ & $4.0 \pm 0.0$ & NT \\
\hline Pseudomonas aeruginosa & $7.5 \pm 0.5$ & -- & $4.3 \pm 0.5$ & NT \\
\hline Bacillus subtilis & $6.0 \pm 0.5$ & $25.7 \pm 1.2$ & $35.0 \pm 1.5$ & NT \\
\hline Staphylococcus aureus & $8.3 \pm 0.5$ & $4.3 \pm 0.6$ & $5.0 \pm 1.0$ & NT \\
\hline Bacillus cereus & $4.7 \pm 0.6$ & $4.5 \pm 0.6$ & $25.6 \pm 1.2$ & NT \\
\hline Aspergillus niger & -- & NT & NT & $5.7 \pm 0.6$ \\
\hline Aspergillus flavus & $2.5 \pm 0.6$ & NT & NT & $4.3 \pm 0.5$ \\
\hline Candida albican & $11.0 \pm 1.0$ & NT & NT & $10.3 \pm 0.5$ \\
\hline Cryptococcus neoformans & $7.3 \pm 1.2$ & NT & NT & $9.3 \pm 1.2$ \\
\hline
\end{tabular}
The ability of WE to scavenge hydroxyl radicals was below

Table 1. Diameter of Zone of Inhibition (mm) of WE from D. indusiata Against Selected Microorganisms 


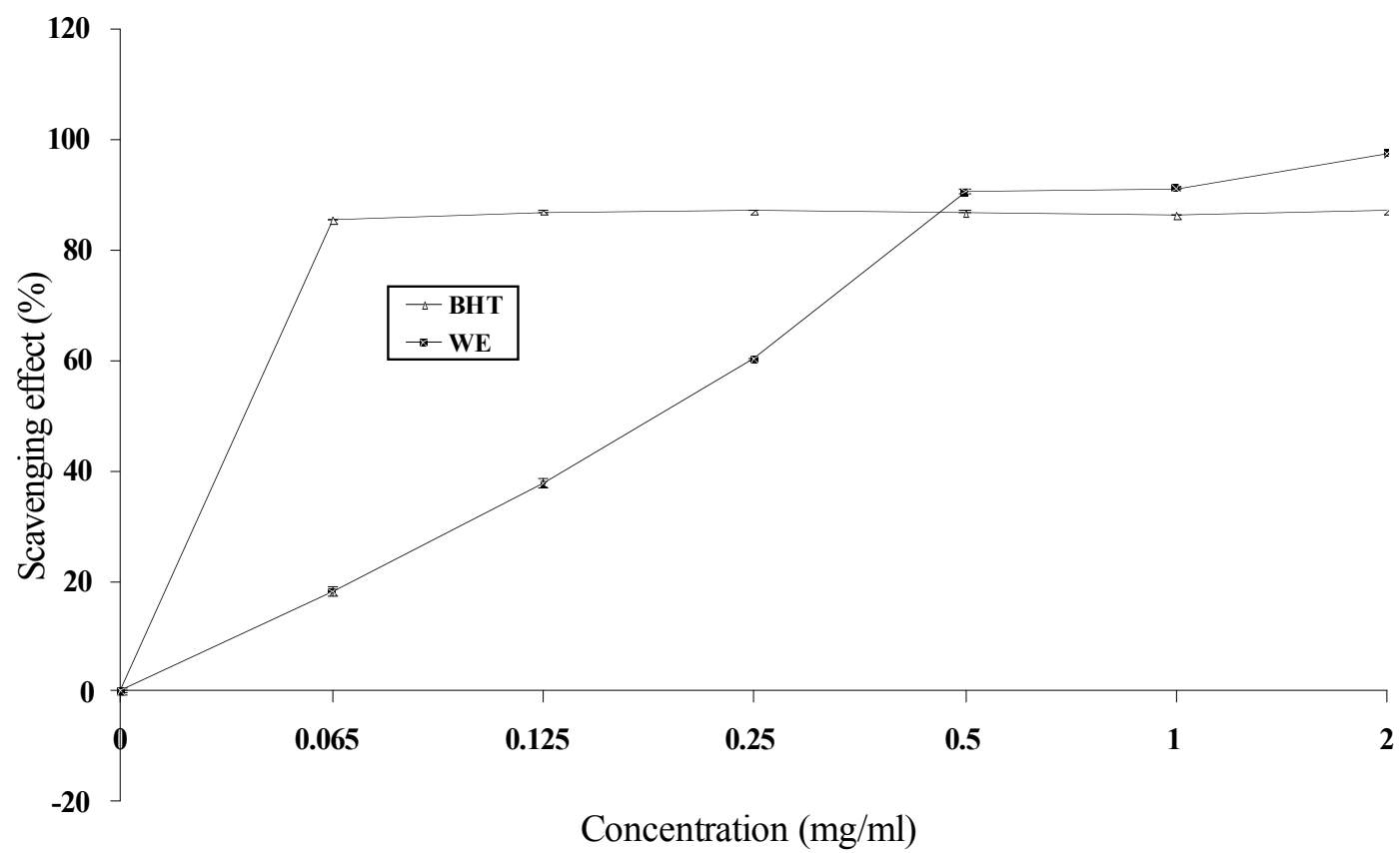

Fig. (1). Free radical scavenging ability of WE from $D$. indusiata. Each value is expressed as mean of three replicates ( $\mathrm{n}=3$ ). BHT: butylated hydroxyl toluene; WE: water extract.

average at concentrations of $0.125-1 \mathrm{mg} / \mathrm{ml}$, however, it was slightly above average $(52.28 \%)$ at $2 \mathrm{mg} / \mathrm{ml}$. The hydroxyl radical scavenging property of WE was lower and significantly different from what was exhibited by BHT (positive control).

\section{Superoxide Anion Scavenging Ability}

The WE exhibited a moderate and concentration dependent superoxide anion activity until $1 \mathrm{mg} / \mathrm{ml}$ concentration (Fig. 4). The ability of WE to scavenge superoxide anion was close to average at $1 \mathrm{mg} / \mathrm{ml}(45.49 \%)$ and $2 \mathrm{mg} / \mathrm{ml}$ $(47.64 \%)$ respectively.

\section{Iron Chelating Activity}

Fig. (5) shows the ferrous ion chelating ability of WE from $D$. indusiata. The extract displayed a very weak chelating activity of $18.56 \%$ at $8 \mathrm{mg} / \mathrm{ml}$ concentration. At concentrations of $0.252 \mathrm{mg} / \mathrm{ml}$, iron chelating effect ranges from $2.6-9.88 \%$. However, there was a slight increase to $15.25 \%$ and $18.56 \%$ in ferrous iron chelating effect at $4 \mathrm{mg} / \mathrm{ml}$ and 8

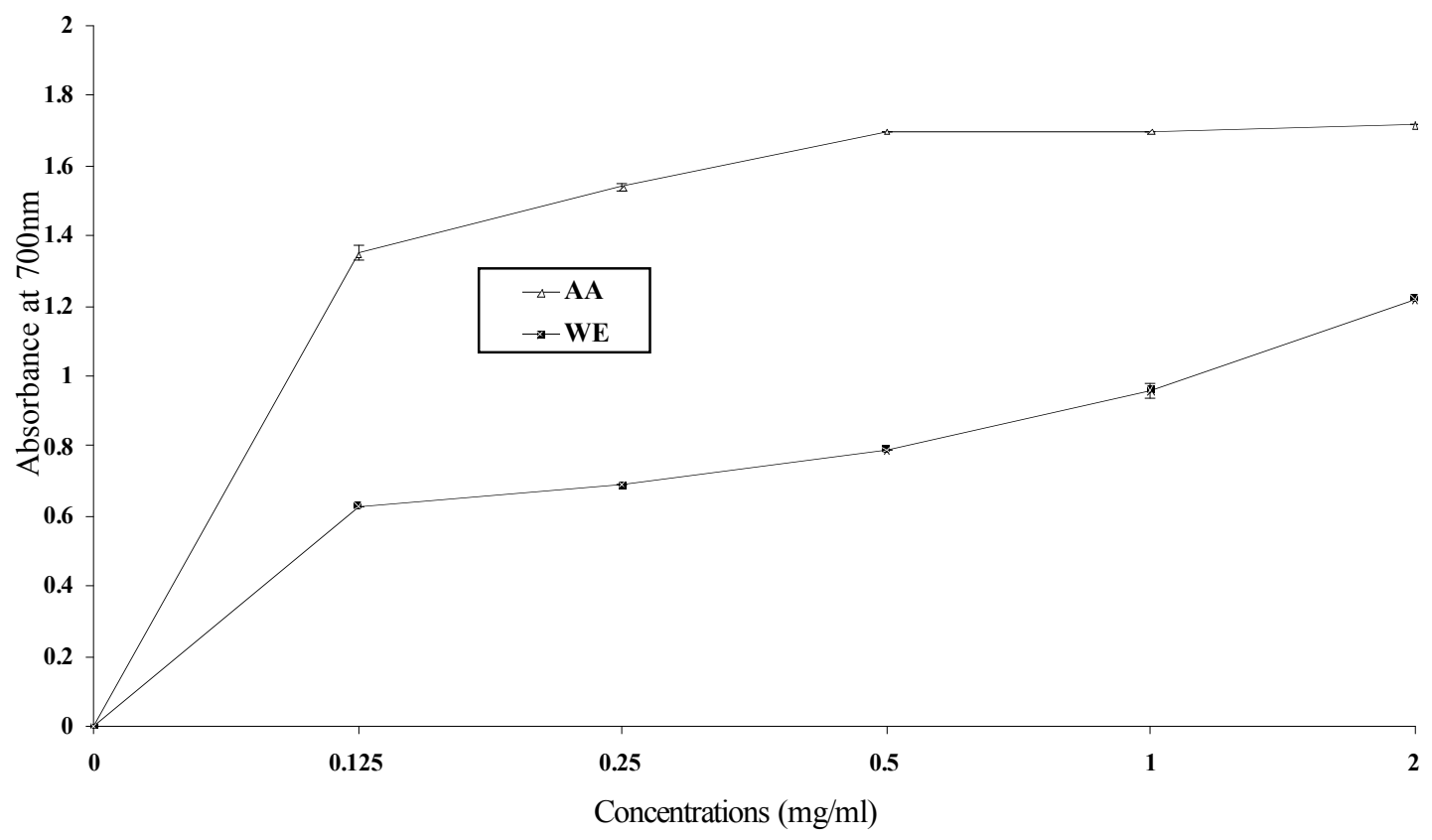

Fig. (2). Reducing power of WE from $D$. indusiata. Each value is expressed as mean of three replicates (n=3). AA: Ascobic acid; WE: Water extract. 


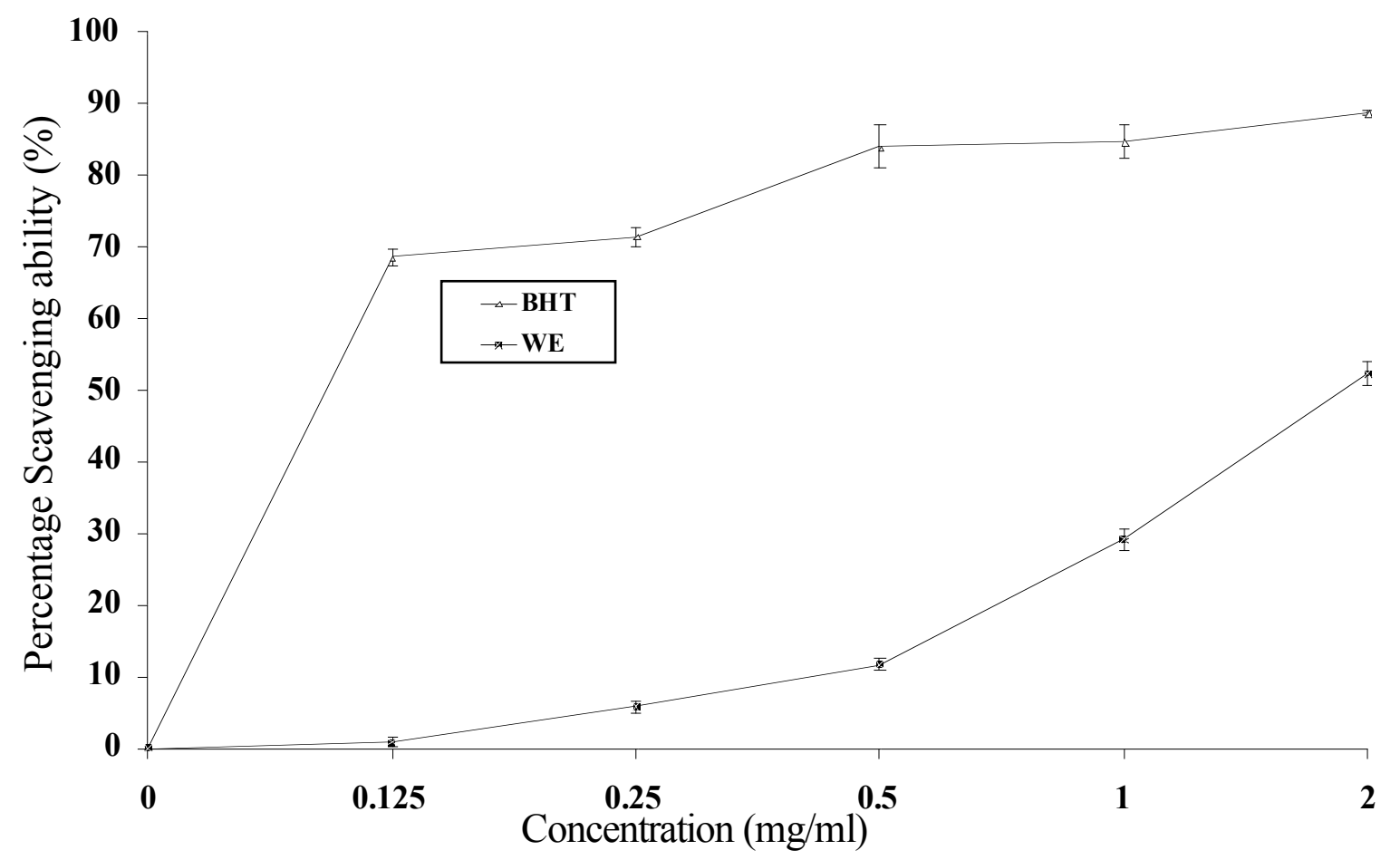

Fig. (3). Hydroxyl radical scavenging ability of WE from D. indusiata. Each value is a mean of three replicates (n=3). BHT: Butylated hydroxyl toluene; WE: Water extract.

$\mathrm{mg} / \mathrm{ml}$ concentrations respectively. Ferrous iron chelating effect of WE was concentration dependent. The iron chelating activity of positive control (EDTA) was significantly higher than WE at all tested concentrations. EDTA displayed iron chelating activity as high as $97.86 \%$ at concentration of $0.25 \mathrm{mg} / \mathrm{ml}$.

\section{DISCUSSION}

Mushrooms have been appreciated as sources of food nutrients for centuries, and, especially, used for medicinal purposes in the orients for centuries [13]. In the present study, antioxidant and antimicrobial activities of aqueous extract from $D$. indusiata, an edible mushroom popular

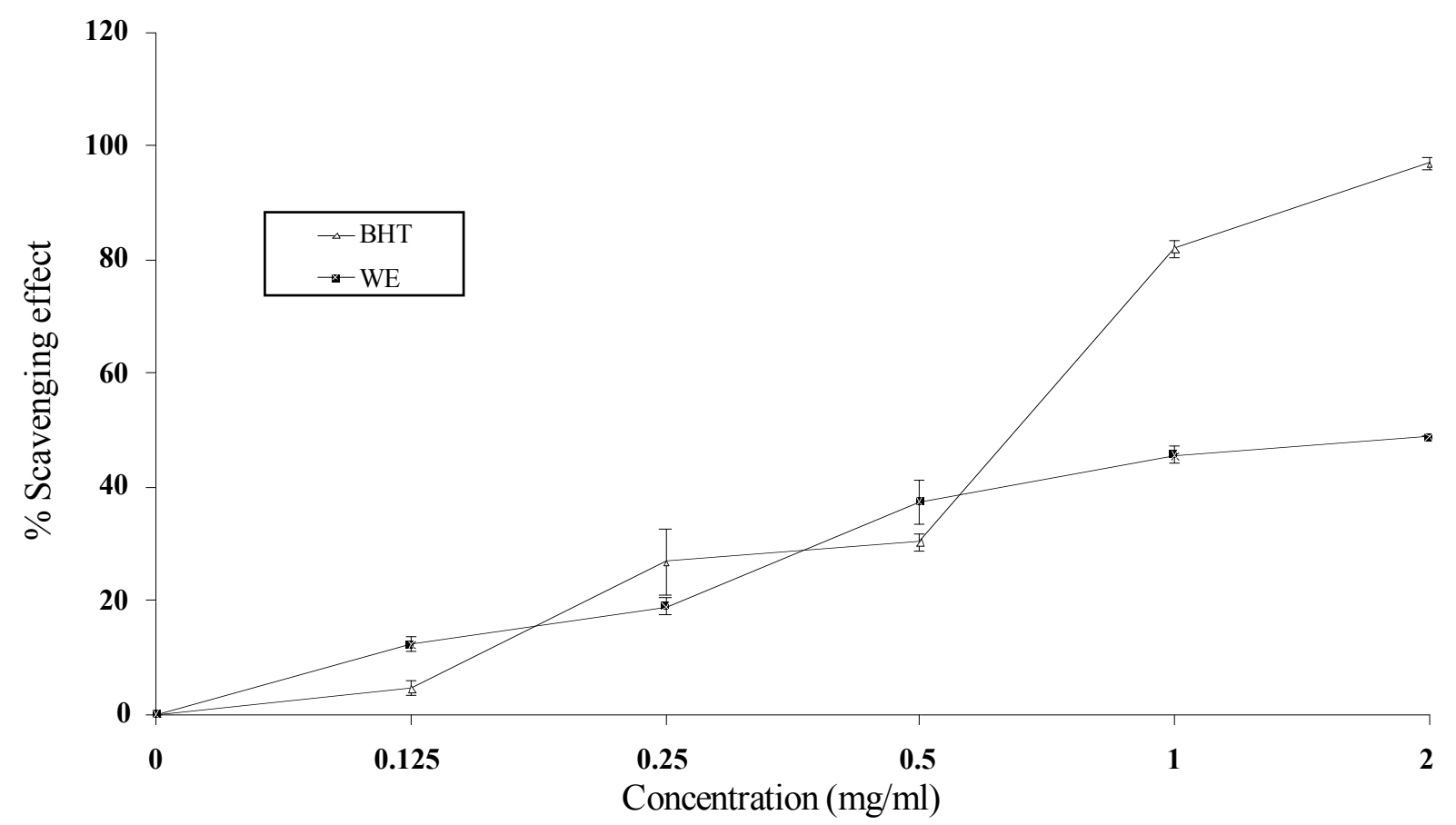

Fig. (4). Superoxide anion scavenging effect of WE from D. indusiata. Each value is expressed as mean of three replicates (n=3). BHT: Butylated hydroxytoluene; WE: Water extract. 


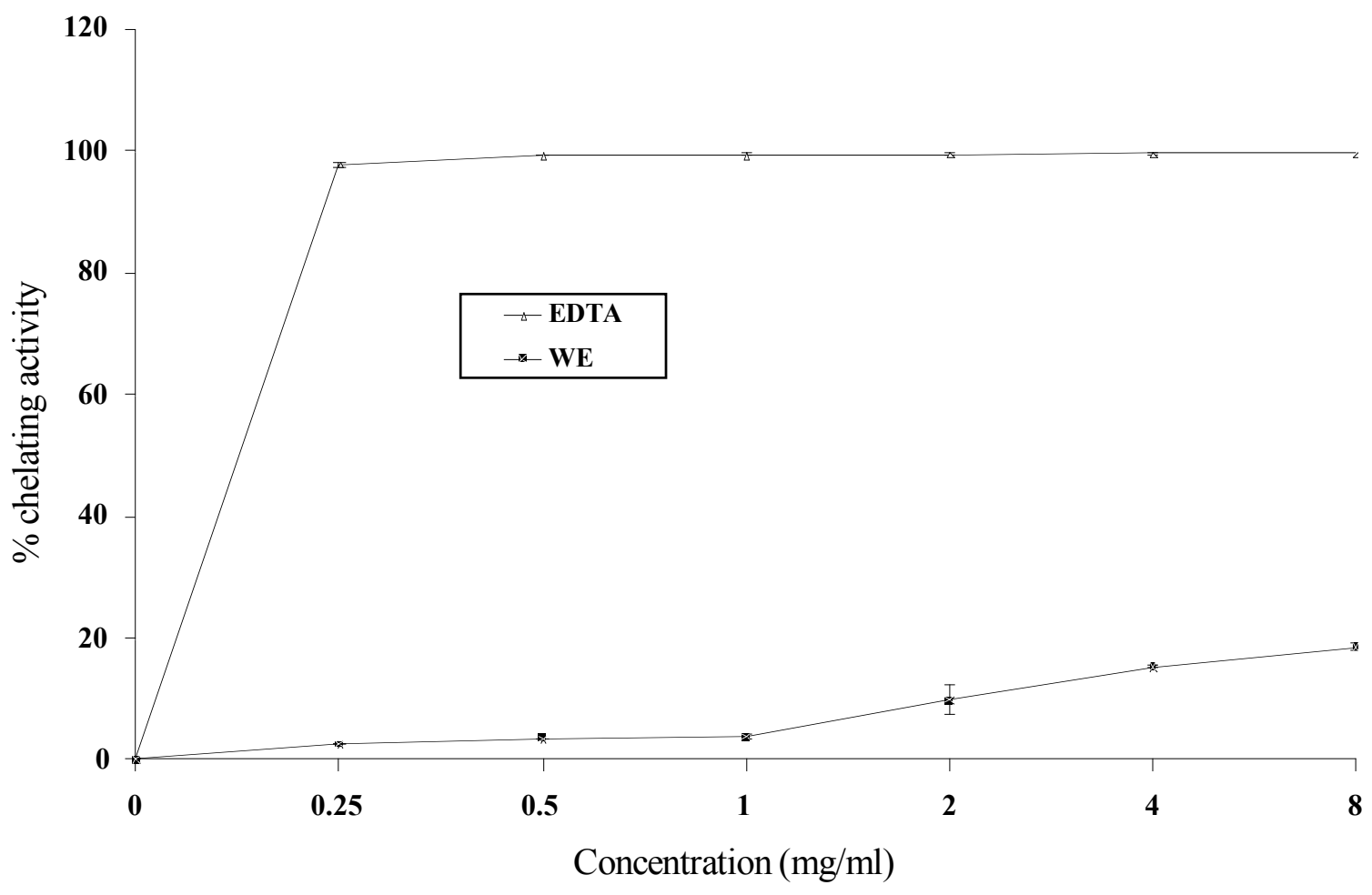

Fig. (5). Ferrous ion chelating activity of WE from D. indusiata. Each value is expressed as mean of three replicates (n=3). EDTA: Ethylene diamine tetraacetic acid; WE: Water extract.

among the Chinese, were assessed by using various in vitro testing systems.

The hot water extract (WE) from D. indusiata was able to inhibit the growth of both bacteria and fungi used as indicator organisms (Table 1), displaying a wide spectrum antimicrobial activity at concentration of $200 \mathrm{mg} / \mathrm{ml}$ whilst Barros et al. [8] reported antimicrobial effect of phenolics extracts of Portuguese wild mushrooms to be between 10 to 300 $\mathrm{mg} / \mathrm{ml}$. The most susceptible bacteria in the present study was Alcaligenes faecalis and the least susceptible was $E$. coli. Among the fungi used as indicators for antimicrobial test, Candida albicans was the most susceptible species to the antimicrobial effect of WE.

$\mathrm{DPPH} \cdot$ assay is a method used to evaluate antioxidant activities in a relatively short time compared with other methods. Moreover, DPPH• is not affected by certain side reactions such as metal chelation and enzyme inhibition which is a major disadvantage associated with laboratorygenerated free radicals [24]. The WE from D. indusiata was a good scavenger of free radicals (Fig. 1). Earlier report on methanolic extract from $D$. indusiata showed an excellent scavenging effect of $92.1 \%$ on DPPH $\bullet$ radicals [17] at concentration of $6.4 \mathrm{mg} / \mathrm{ml}$. However, the WE from $D$. indusiata exhibited $97.58 \%$ free radical scavenging ability at a lower concentration of $2 \mathrm{mg} / \mathrm{ml}$. The WE also show a good reducing ability when compared to methanolic extract of $D$. indusiata. The reducing power (1.20) of WE at $2 \mathrm{mg} / \mathrm{ml}$ concentration was higher than 1.09 reducing power at $3 \mathrm{mg} / \mathrm{ml}$ concentration reported for methanolic extract from $D$. indusiata by Mau et al. [17].

The WE from $D$. indusiata also exhibited moderate and concentration dependent hydroxyl radical scavenging ability
(Fig. 3). Hydroxyl radicals are highly reactive [25] and can induce severe damage to adjacent molecules [26]. Mau et al. [27] had earlier reported a concentration dependent increase in the scavenging abilities of all hot water extracts from Ganoderma tsugae on hydroxyl radicals while methanolic extract from $G$. tsugae showed a non concentration dependent hydroxyl radical scavenging ability. Similarly, the WE obtained from $D$. indusiata exhibited a concentration dependent activity (Fig. 3).

Superoxide anions are biologically important since they are very harmful to cellular components of biological systems because their decomposition can lead to the formation of stronger oxidative species such as singlet oxygen and hydroxyl radicals [25, 28]. Superoxide anion scavenging effect of the WE is also moderate and concentration dependent until $1 \mathrm{mg} / \mathrm{ml}$ concentration (Fig. 4). Dong and Yao [29] had earlier observed that hot water extract from natural and cultured mycelium of $C$. sinensis had a better superoxide scavenging effect than methanolic extract. Hence, the WE from $D$. indusiata hold promise as a source of bioactive that may effectively scavenge superoxides.

The WE displayed a very weak chelating activity of $18.55 \%$ at $8 \mathrm{mg} / \mathrm{ml}$ concentration. Weak ferrous iron chelating effect of $17.1 \%$ at concentration of $3 \mathrm{mg} / \mathrm{ml}$ had earlier been reported for methanolic extract from $D$. indusiata [17].

The present report shows that the WE from $D$. indusiata may be effective as antioxidant and antimicrobial agents. The higher antioxidative properties, observed for the WE when compared with antioxidative activity of methanolic extract from $D$. indusiata previously reported by Mau et al. [17], may be due to the presence of water soluble phenolics in WE. Water soluble phenolics have been reported to play 
important role in reversing oxidative stress [30]. Puttaraju et al. [31] have also reported that antioxidant activity of water extract from Termitomyces species was better than methanolic extract. Moreover, antimicrobial activity of the WE was well pronounced against both gram positive and gram negative bacteria. Furthermore, Candida albicans, a pathogenic yeast, was also susceptible to the antimicrobial action of the extract. The WE from $D$. indusiata may therefore hold promise as a good source of bioactive for biopharmaceutical exploitation. Further work aimed at identification of the specific biological agents responsible for antioxidant and antimicrobial properties in WE is the next focus.

\section{ACKNOWLEDGEMENTS}

The authors wish to acknowledge the financial support of CAS-TWAS. OVO is a recipient of the CAS-TWAS Postdoctoral Fellowship. This work is also supported by the National Science and Technology Supporting Project (2008BADA1B06) and National Basic Research Program of China (2009CB522302) operated by the Ministry of Science and Technology of China.

\section{REFERENCES}

[1] Fasidi IO, Kadiri M. Induction of edible sclerotia of Plerotus tuberregium (Fr.) Singer in the Laboratory. Ann Appl Biol 1990; 117 : 295-8.

[2] Sivrikay H, Bacak L, Saracbasi A, et al. Trace elements in Pleurotus sajor-caju cultivated on chemithermomechanical pulp for biobleaching. Food Chem 2002; 79: 173-6.

[3] Sagakami H, Aohi T, Simpson A, et al. Induction of immunopotentiation activity by a protein-bound polysaccharide, PSK. Anticancer Res 1991; 11: 993-1000.

[4] Wasser SP, Weis AL. Medicinal properties of substances occurring in higher basidiomycetes mushrooms: current perspectives (review). Intern J Med Mushs 1999; 1: 31-62.

[5] Demain AL. Pharmaceutically active secondary metabolites of microorganisms. Appl Microbiol Biotech 1999; 52(4): 455-63.

[6] Miuzino T. The extraction and development of antitumor active polysaccharides from medicinal mushrooms in Japan (Review). Intern J Med Mushs 1999; 1: 9-30.

[7] Mau JL, Chang C-N, Huang S-J, et al. Antioxidant properties of methanolic extracts from Grifola frondosa, Morchella esculenta and Termitomyces albuminosus mycelia. Food Chem 2004; 87: 111-8.

[8] Barros L, Calhelha RC, Vaz JA, et al. Antimicrobial activity and bioactive compounds of Portuguese wild edible mushrooms methanolic extracts. Eur Food Res Technol 2007; 225: 151-6.

[9] Ferreira ICFR, Baptista P, Vilas-Boas M, et al. Free-radical scavenging capacity and reducing power of wild edible mushrooms from northeast Portugal: individual cap and stipe activity. Food Chem 2007; 100: 1511-6.

[10] Kitzberger CSG, Smânia JrA, Pedrosa RC, et al. Antioxidant and antimicrobial activities of shiitake (Lentinula edodes) extracts obtained by organic solvents and supercritical fluids. J Food Eng 2007; 80:631-8
[11] Velioglu YS, Mazza G, Gao L, et al. Antioxidant activity and total phenolics in selected fruits, vegetables, and grain products. J Agric Food Chem 1998; 46: 4113-7.

[12] Martinez-Tome M, Jimenez A, Ruggieri S, et al. Antioxidant properties of Mediterranean spices compared with common food additives. J Food Prot 2001; 64: 1412-9.

[13] Lindequist U, Niedermeyer THJ, Julich W-D. The pharmacological potential of mushrooms-Review. Evid Based Complement Alternat Med 2005; 2(3): 285-99.

[14] Lovy A, Knowles B, Labbe R, et al. Activity of edible mushrooms against the growth of Human T4 Leukemic Cancer Cells, HeLa Cervical Cancer Cells, and Plasmodium falciparum. J Herbs Spices Med Plants 1999; 6: 49-57.

[15] Isaka M, Tantichareon M, Kongsaeree $\mathrm{P}$, et al. Structures of Cordypyridones A-D, Antimalarial N-Hydroxy- and N-Methoxy-2pyridones from the Insect Pathogenic Fungus Cordyceps nipponica. J Org Chem 2001; 66: 4803-8.

[16] Jong SC, Birmingham JM. Medicinal and therapeutic value of the Shiitake mushroom. Adv Appl Microbiol 1993; 39: 153-84.

[17] Mau JL, Lin H-C, Song S-F. Antioxidant properties of several specialty mushrooms. Food Res Intern 2002; 35: 519-26.

[18] Tan J, Hu Y. Antimicrobial actions of Dictyophora indusiata Fissher. J Hunnan Agric Univ 1999; 25(6): 479-82 (Article in Chinese).

[19] Tan D-F, Wu R-J, Liang M, et al. Studies on chemical compositions and and antimicrobial activity of volatile oil of Dictyoophora echinovolvata. Mycosystema 2002; 21(2): 228-33 (Article in Chinese).

[20] Blois MS. Antioxidants determination by the use of a stable free radical. Nature 1958; 181: 1199-200.

[21] Yen G.-C, Chen H-Y. Antioxidant activity of various tea extract in relation to their antimutagenicity. J Agric Food Chem 1995; 43: 27 32.

[22] Halliwell B, Gutteridge JMC, Aruoma OI. The deoxyribose method: a simple 'Test-Tube' assay for determination of rate constants for reactions of hydroxyl radicals. Anal Biochem 1987; 165: 215-9.

[23] Decker EA, Welch B. Role of ferritin as a lipid oxidation catalyst in muscle food. J Agric Food Chem 1990; 38: 674-7.

[24] Amarowicz P, Pegg RB, Rahimi-Moghaddam P, et al. Free-radical scavenging capacity and antioxidant activity of selected plant species from the Canadian prairies. Food Chem 2004; 84: 551-62.

[25] Zhao G.-R, Xiang Z-J, Ye T-X, et al. Antioxidant activities of Salvia miltiorrhiza and Panax notoginseng. Food Chem 2006; 99 : 767-74.

[26] Chance B, Sies H, Boveris A. Hydroperoxide metabolism in mammalian organs. Physiol Rev 1979; 59: 527-605.

[27] Mau J-L, Tsai S-Y, Tseng Y-H, et al. Antioxidant propertiesof hot water extracts from Ganoderma tsugae Murrill. LWT - Food Sci Technol 2005; 38: 589-97.

[28] Korycka-Dahl M, Richardson M. Photogeneration of superoxide anion in serum of bovine milk and in model systems containing riboflavin and aminoacids. J Dairy Sci 1978; 61: 400-7.

[29] Dong C-H, Yao Y-J. In vitro evaluation of antioxidant activities of aqueous extracts from natural and cultured mycelia of Cordyceps sinensis. LWT. Food Sci Technol 2008; 41: 669-77.

[30] Kohen R, Gati I. Skin molecular weight antioxidants and their role in aging and antioxidative stress. Toxicology 2000; 148: 149-57.

[31] Puttaraju NG, Venkateshaiah SU, Dharmesh SM, et al. Antioxidant activity of indigenous edible mushrooms. J Agric Food Chem 2006; 54(26): 9764-72. 